\title{
Research on Production Strategy with Carbon Emissions
}

\author{
Honglei Tang ${ }^{*}, 1,2$ and Guofang Song ${ }^{3}$ \\ ${ }^{I}$ School of Management, Shanghai University, Shanghai 200000, P.R. China \\ ${ }^{2}$ Huzhou Teachers College, Huzhou 310000, P.R. China \\ ${ }^{3}$ Guofang Song, School of Management, Shanghai University, Shanghai 200000, P.R. China
}

\begin{abstract}
This paper mainly studied the influence on the carbon emission permits and trading on the production strategy for manufacturing enterprises. The enterprises might obtain carbon emission permits in three different ways, i.e. government quota, market trading and purification treatment. The enterprises must make a tradeoff between them. The characteristic of purifying cost was analyzed. Then, an optimal production model with carbon emission permits and trading was established. Finally, a typical numerical experiment was employed to show the influence of the parameters on optimal production decisions.
\end{abstract}

Keywords: Carbon emissions permits and trading, carbon emission reduction, production strategy.

\section{INTRODUCTION}

With the development of human society and economical improvement, harmful emissions increased accordingly, hence it increased environmental disasters. The most typical example of this is, carbon dioxide emissions have been proven to be one of the main culprit of global warming in recent years. Come into effect in 2005 set by the Kyoto Protocol International Convention for the control and the trading market means to effectively achieve emissions reduction effects of "emissions mechanisms": 1) International Emission Trade (IET) allows Annex I countries (mainly developed) transfer between parts of their allowed emissions; 2) Joint Implementation mechanism (JI) allows Annex I countries from its investment projects in other industrialized countries have obtained carbon emissions credit, actual result corresponds to transfers between industrialized countries with equal amounts of emission reduction units; 3) clean development mechanism (CDM), allows Annex I national of investors from its in developing countries implementation of, and conducive to developing countries sustainable development of emissions project in the gets "by nuclear card of emissions volume (CERs)", is allows Annex $\mathrm{I}$ in the of national funded support no emissions obligations of national by industrial technology, and activities, reduced greenhouse gas of emissions volume and arrived top annex I national of emissions index. In this way, emissions quotas as factors of production, emissionsdependent enterprises under quota self-specification, exceeding required with emission rights trading market to other enterprises or green purchase additional emissions rights, otherwise, it will be subject to legal sanctions; by production or purification process of enterprises

*Address correspondence to this author at the School of Management, Shanghai University, Shanghai 200000, P.R. China; Huzhou Teachers College, Huzhou 310000, P.R. China; Tel: +8613738231232 ;

Fax: +86-572-2321105; E-mail: hlttj@126.com technological innovation and access to emission-savings you can use trading platform in the market to obtain additional revenue.

Currently, emission trading related research is mainly focused on the macro level, such as bilateral trading rules between economies of the emissions; how to start the game in the established rules for the economies and the economic effect of emissions trading and emission reduction policy on different countries and industries. In view of the electric power industry, Monica and Francesco studied on the prevailing European emissions trading mechanism, carbon emissions trading price for electricity market pricing strategy, and compares the market power (Market Power) environment and competitive environment (Perfect Competition) under the influence of difference [1]. Kara et al. have taken Finland as an example, discussed the European emissions trading to power market and power users influence [2]. Tsikalakis and Hat ziargyriou comparatively analyzed the carbon emissions trading was permitted or not under the environmental benefits of distributed generation [3]. Damien and Philippe in iron and steel industry as an example to discuss the European emissions trading scheme for production of the industry and the income effect [4]. Other scholars, such as Cramton and Kerr, Knut, Streimikiene and Roos also have analyzed the influence of emissions trading for different industries and countries from different point of view $[5,6]$. Until now, there has been little documentation from a microscopic perspective to study the emission rights trading. Emissions and become an asset when factors of production, several aspects of enterprise production will be significantly affected in particular, from the micro level is necessary to discuss this issue. Sundarakani et al. have used Lagrangian and Eulerian traffic analysis method to establish supply chain carbon emission measurement model for supply chain design, provided the basis for low carbon [7]. Bode has studied the assignment problem to European power industry as the 
research background, from the multi cycle, emission permits and trading of emission rights [8]. Benjaafar studied the carbon emissions factors in simple supply chain system, respectively, established a strict emission quota model, carbon tax model, cap and trade model and carbon offset model for supply chain [9]. Piecyk and Mckinnon have divided the influence factors of carbon emissions for transport of goods by road into structural, merchantability, operation, functionality, external sexual, relationship of products, and established the road transport model of carbon emissions in 2020 from the pessimistic and optimistic Outlook [10]. Above all, this article as an example of a single manufacturing enterprise, analysis on a given emission limits and allowed emissions free trading optimal decision of production problems.

\section{BASIC ASSUMPTIONS AND PARAMETERS}

Government quotas, market trading and purification of three sources of emissions, as well as single-cycle production, emissions scenarios, combined with the reality, we make the following assumptions:

(1) Carbon emissions can be freely traded and that a range of carbon emission rights market supply;

(2) If industry is a high-emissions industries with monopolistic or oligopolistic nature, such as energy, electric power, chemical industry, product market price is determined by production. Assuming the price yield of linear functions;

(3) Assume that businesses need to produce out of the production technology, also need to be put into use two types of factors of production, one is the production of high carbon elements; The other one is the production of low carbon element, and these two factors of production number of input variable, and with incomplete alternative. The production function can be determined by the kebudaogelasi function of the enterprise;

(4) In determining under the production technical level, finished product depending on the amount of raw materials used by the carbon emissions of certain;

(5) Carbon emissions using CCS technology processing or purification technology, and carbon emissions savings, and its treatment costs with carbon emissions increase while accelerating, this is consistent with reality. The symbols of the main parameters involved in this article is summarized below:

$q$ : Producers to be the finished product the total amount of production, decision variables; and $q=f\left(x_{1}, x_{2}\right)=A x_{1}^{\alpha} x_{2}^{\beta}$, A represents enterprise production technology, $\mathrm{A}>0$; $x_{1}, x_{2}$ represent elements of production of high carbon and low carbon number of factors of production inputs, and $x_{1}>0, x_{2}>0 ; \alpha, \beta$ respectively for the two categories of factors of production input on product factors.

$\mathrm{E}(\mathrm{q})$ : Actual emissions from production, is the yield function of q. Without loss of generality, this article according to the different production factors determine different emission factors, $E(q)=e q=e_{1} x_{1}+e_{2} x_{2}$;
$E_{g}$ : Carbon emissions quotas from the Government;

$c_{m}$ : Carbon emissions trading market unit of carbon emissions trading;

$E_{m}$ : Carbon emissions obtained through market transactions, $E_{m}>0$ is buy; $E_{m}<0$ is sell.

$p(q)$ : Finished product market prices, determined by the output. Think about $p(q)=K-\gamma q$;

C: Cost of production, determined by two factors of production: $C=\delta q=c_{1} x_{1}+c_{2} x_{2}$;

$\eta$ : Purification levels of carbon emissions, $0 \leq \eta \leq 1$;

$c(\eta)$ : Unit purification cost under the purification level $\eta$, Continuous and differential and $c(0)=0, c(1)=+\infty$, $c^{\prime}(\eta)>0, c^{\prime \prime}(\eta)>0$;

$E_{p}$ : the quantity of treated carbon emissions, decision variables, $0 \leq E_{p} \leq E(q)$;

$E_{s}$ : the credit of access to the net carbon emissionsreduction by purification, $E_{s}=\eta E_{p}$.

\section{MATHEMATICAL MODEL}

This article is intended to discuss carbon emissions quotas on production and trading company of production optimization problem, it needs to consider the costs associated with carbon emissions carbon emissions quotas-purchase cost and processing costs, purchasing costs of the two production factors in the production process, while other costs can be ignored, this does not affect the analysis results. The production enterprise's net profit is:

$$
\pi=q p(q)-C(q)-c_{m} E_{m}-c(\eta) E_{p}
$$

Earlier assumptions, manufacturer of carbon emissions come from three main sources: Government quota $E_{g}$, adopted by carbon emission savings of $E_{s}$ and carbon emission credits market to purchase some $E_{m}$ eventually will not exceed the total carbon emissions-carbon emissions, is

$E(q) \leq E_{g}+E_{s}+E_{m}$

Enterprise is rational, and carbon emissions through market transactions, the single phase case, once carbon emissions surpluses, enterprises will also be put on the market for sale. So the above inequality is converted to:

$E(q)=E_{g}+E_{s}+E_{m}$

According to equation (3):

$E_{m}=E(q)-E_{g}-E_{s}=E(q)-E_{g}-\eta E_{p}$

Equation (4) into equation (1):

$$
\begin{aligned}
& \pi=q p(q)-C(q)-c_{m}\left[E(q)-E_{g}-\eta E_{p}\right]-c(\eta) E_{p} \\
& \quad=q p(q)-C(q)-c_{m} E(q)+ \\
& {\left[c_{m} \eta-c(\eta)\right] E_{p}+c_{m} E_{g}}
\end{aligned}
$$


Apart from Government quotas, there are two kinds of carbon emission credits of access: if the purification is $\eta$, and the quantity is $\mathrm{E}_{\mathrm{p}}$, the cost is $c(\eta), \eta E_{p}$ is the saving carbon emissions, that is, to CCS technology and purification treatment access unit cost of carbon emission savings: $\frac{c(\eta)}{\eta}$; If purchased from the market, unit procurement cost for carbon emissions: $c_{m}$.

\section{MODEL ANALYSIS}

When the producers of carbon emissions levels $\eta$ is fixed, analysis of relationship between $\pi$ and $E_{p}, E_{p} \in[0, E(q)]$ :

(1) if $\frac{c(\eta)}{\eta}<c_{m}$, we can get $\frac{\partial \pi}{\partial E_{p}}>0$ from the equation (5), has $E_{p}=E(q)$, is: CCS technology or purification processing way than market purchase way cost more low, or from sold carbon emissions credit angle see is exists profit space, production Chamber of Commerce priority select CCS technology or purification processing all emissions real, insufficient part is from trading market purchased into, surplus part is put trading market earned post. In this case, (4) should rephrase as follows:

$E_{m}=(1-\eta) E(q)-E_{g}$

So:

$\pi=q p(q)-C(q)-\left[c_{m}(1-\eta)+c(\eta)\right] E(q)+c_{m} E_{g}$

Manufacturers make optimal decisions about yield $\mathrm{q}$ to maximize its profits. So:

$\frac{\partial \pi}{\partial q}=p(q)+q p^{\prime}(q)-C^{\prime}(q)-\left[c_{m}(1-\eta)+c(\eta)\right] E^{\prime}(q)=0$

Without loss of generality, consider this article linear inverse demand function, $p(q)=K-\gamma q$, linear carbon emission $E(q)=e q$ and linear cost function $C(q)=\delta q$, which can produce optimal production is:

$q^{*}=\frac{K-\delta-e\left[c_{m}(1-\eta)+c(\eta)\right]}{2 \gamma}$

Under such optimal production decision, manufacturer of carbon emissions and carbon emissions savings, obtained by trading carbon emissions balance or surplus in the market, and the maximum level of profits, respectively:

$E_{p}=e q^{*} ; E_{s}=\eta e q^{*}$

$E_{m}=(1-\eta) E\left(q^{*}\right)-E_{g}=(1-\eta) e q^{*}-E_{g}$

$\pi^{*}=\left[K-\delta-e c_{m}(1-\eta)-e c(\eta)\right] q^{*}-\gamma\left(q^{*}\right)^{2}+c_{m} E_{g}$
(2) if $\frac{c(\eta)}{\eta}=c_{m}$, Enterprise way on carbon emissions and carbon emissions is equivalent to purchases in terms of cost-benefit of the market, namely: $E_{p}$ take $[0, E(q)]$ any value within the range, has no impact on production enterprise income. So:

$\pi=q p(q)-C(q)-c_{m} E(q)+c_{m} E_{g}=q(K-\gamma q)-\delta q-c_{m} e q+c_{m} E_{g}$

Optimal conditions is:

$\frac{\partial \pi}{\partial q}=K-2 \gamma q-\delta-e c_{m}=0$

Optimal yield under such circumstances as:

$q^{*}=\frac{K-\delta-e c_{m}}{2 \gamma}$

$E_{m}$ is: $E_{m}=e q^{*}-E_{g}-\eta E_{p}$

(3) if $\frac{c(\eta)}{\eta}>c_{m}, \frac{\partial \pi}{\partial E_{p}}<0 . \pi$ is $E_{p}$ monotone function reduction, there will be $E_{p}=0$. Namely, manufacturers will not take or purification technology of CCS technology, all carbon emissions are direct emissions quotas is insufficient to meet production needs or if the Government there is surplus, by buying or selling carbon emissions trading market. In this case, the profit of enterprise is equation (13), so the best quantity is equation (15), and $E_{m}=e q^{*}-E_{g}$; $E_{p}=0$.

\section{NUMERICAL ANALYSIS}

From the above analysis, the optimal strategy of production Enterprise in different situations is shown in Table 1.

If the government quotas $E_{g}=100$, the inverse demand function of Products is: $p(q)=151-0.5 q$, per unit cost of production is: $\delta=1$, it can be calculated that the optimal quantity of enterprise is 150 , and the max profit us 11250 , without the restriction on carbon emissions. The Purification cost function of carbon emissions is $c(\eta)=\frac{10 \eta}{1-\eta}$.

For the further research on carbon emissions trading prices $c_{m}$ and levels of carbon emissions purification parameters $\eta$ which are impacted on production strategy and optimize results, we focused on these two parameters for sensitivity analysis. As shown by following Tables $\mathbf{2}$ and $\mathbf{3}$, results display: (1) With the reduction of carbon emissions trading price $c_{m}$, corporate profits decreased and then increased, purification levels gradually decreased until purification is not selected and all right to buy offset carbon 
Table 1. Production Strategy of Enterprise Under Different Situations

\begin{tabular}{|c|c|c|c|c|}
\hline \multirow[b]{2}{*}{ Variable } & \multirow[b]{2}{*}{ Cost of No Restrictions on Carbon Emissions } & \multicolumn{3}{|c|}{ Cost of Carbon Emission is Not Zero } \\
\hline & & $\frac{c(\eta)}{\eta}<c_{m}$ & $\frac{c(\eta)}{\eta}=c_{m}$ & $\frac{c(\eta)}{\eta}>c_{m}$ \\
\hline$q^{*}$ & $\frac{K-\delta}{2 \gamma}$ & $q^{*}=\frac{K-\delta-e\left[c_{m}(1-\eta)+c(\eta)\right]}{2 \gamma}$ & $q^{*}=\frac{K-\delta-e c_{m}}{2 \gamma}$ & $q^{*}=\frac{K-\delta-e c_{m}}{2 \gamma}$ \\
\hline$E_{p}$ & 0 & $E_{p}=e q^{*}$ & $\forall E_{p} \in[0, E(q)]$ & 0 \\
\hline$E_{s}$ & 0 & $E_{s}=\eta e q^{*}$ & $E_{s}=\eta E_{p}$ & 0 \\
\hline$E_{m}$ & 0 & $E_{m}=(1-\eta) e q^{*}-E_{g}$ & $E_{m}=e q^{*}-E_{g}-\eta E_{p}$ & $E_{m}=e q^{*}-E_{g}$ \\
\hline$\pi^{*}$ & $\begin{array}{l}(K-\delta) q^{*} \\
-\gamma q^{* 2}\end{array}$ & $\begin{array}{l}\pi^{*}=\left[K-\delta-e c_{m}(1-\eta)-e c(\eta)\right] q^{*} \\
-\gamma\left(q^{*}\right)^{2}+c_{m} E_{g}\end{array}$ & $\begin{array}{l}\pi=q^{*}\left(K-\gamma q^{*}\right)- \\
\delta q^{*}-c_{m} e q^{*}+c_{m} E_{g}\end{array}$ & $\begin{array}{l}\pi=q^{*}\left(K-\gamma q^{*}\right) \\
-\delta q^{*}-c_{m} e q^{*}+c_{m} E_{g}\end{array}$ \\
\hline
\end{tabular}

$\mathrm{q}^{*}$ represents the optimal production, $\pi^{*}$ represents the maximum level of profits, and $\mathrm{E}_{\mathrm{p}}^{*}$ represents the quantity of treated carbon emissions under the optimal production, $\mathrm{E}_{\mathrm{s}}^{*}$ represents the quantity of the carbon emissions reduced by purification under the optimal production, $\mathrm{E}_{\mathrm{m}}^{*}$ represents the quantity of carbon emissions obtained through market transactions under the optimal production

Table 2. Sensitivity Analysis on the Volatility About the Carbon Emissions Trading Price on Business Decisions and the Optimal Results

\begin{tabular}{|c|c|c|c|c|c|}
\hline$c_{m}$ & $q^{*}$ & $E_{p}^{*}$ & $E_{s}^{*}$ & $E_{m}^{*}$ & $\pi^{*}$ \\
\hline \hline 5 & 145 & 0 & 0 & 0 & 45 \\
11012.5 \\
\hline 10 & 140 & 0 & 0 & 35 & 10800 \\
\hline 15 & 135 & 0 & 0 & 30 & 10612.5 \\
\hline 20 & 130 & 127.5 & 63.75 & -36.25 & 10450 \\
\hline 25 & 127.5 & 125 & 62.5 & -37.5 & 10628.13 \\
\hline 30 & 125 & 122.5 & 61.25 & -38.75 & 11003.13 \\
\hline 40 & 122.5 & 120 & 60 & -40 & 11200 \\
\hline
\end{tabular}

$\mathrm{q}^{*}$ represents the optimal production, $\pi^{*}$ represents the maximum level of profits, and $\mathrm{E}_{\mathrm{p}}^{*}$ represents the quantity of treated carbon emissions under the optimal production, $\mathrm{E}^{*}$ represents the quantity of the carbon emissions reduced by purification under the optimal production, $\mathrm{E}_{\mathrm{m}}^{*}$ represents the quantity of carbon emissions obtained through market transactions under the optimal production.

Table 3. Sensitivity Analysis on the Purification Cost Parameter $\eta$ on Business Decisions and the Optimal Results

\begin{tabular}{|c|c|c|c|c|c|}
\hline$\eta$ & $q^{*}$ & $E_{p}^{*}$ & $E_{s}^{*}$ & $E_{m}^{*}$ & 10000 \\
\hline \hline 0.0 & 100 & 0 & 0 & 0 & 10428.1 \\
\hline 0.1 & 122.9 & 122.9 & 12.29 & 10.61 & 10626.13 \\
\hline 0.2 & 123.5 & 123.5 & 24.7 & -1.2 & 10775.05 \\
\hline 0.3 & 124.7 & 124.7 & 37.41 & -12.71 & 10853.81 \\
\hline 0.4 & 125.33 & 125.33 & 50.13 & -24.8 & 10812.5 \\
\hline 0.5 & 125 & 125 & 62.5 & -37.5 & 10564.5 \\
\hline 0.6 & 123 & 123 & 73.8 & -50.8 & 10200 \\
\hline 0.7 & 120 & 0 & 0 & 20 & 10200 \\
\hline 0.8 & 120 & 0 & 0 & 20 & 10200 \\
\hline 0.9 & 120 & 0 & 0 & 20 & \\
\hline
\end{tabular}

$\mathrm{q}^{*}$ represents the optimal production, $\pi^{*}$ represents the maximum level of profits, and $\mathrm{E}_{\mathrm{p}}^{*}$ represents the quantity of treated carbon emissions under the optimal production, $\mathrm{E}_{\mathrm{s}}^{*}$ represents the quantity of the carbon emissions reduced by purification under the optimal production, $\mathrm{E}_{\mathrm{m}}^{*}$ represents the quantity of carbon emissions obtained through market transactions under the optimal production 
emissions balance, while the finished product output has been growing in the State enterprises by selling excess emissions into buying emission rights; (2) With $\eta$ falling corporate profits increased and then decreased, purification level from scratch until gradually increase enterprise by buying emission rights into selling emissions rights.

\section{CONCLUSION}

With the "low carbon economy" development of carbon emission rights gradually became an important resource for enterprises, it will have a certain impact on enterprise production and management decisions. This company in carbon production management decision problems under the constraint of the right, the establishment of a carbon constrained optimal production decisions and optimal cleaning strategies and optimal carbon trading strategy. The conclusion of this article is significant for the production decision of enterprises.

But in the course of research for this article, product prices and carbon prices as exogenous variables to consider, not taking into account their randomness, in follow-up studies, you can further expand. In addition, this article is considered a single optimal strategy aspect of a case, in subsequent studies could be considered when the demand for products, product prices and carbon when the price of a random process, optimal strategies of enterprises in different stages.

\section{CONFLICT OF INTEREST}

The authors confirm that this article content has no conflict of interest.

\section{ACKNOWLEDGEMENTS}

Nature Science Foundation of Zhejiang Province (No:LY12G03002); Social Science Foundation of Zhejiang Province(No:12JCGL16YB).

\section{REFERENCES}

[1] B. Monica, and G. Frabcesco, "Electricity pricing under 'carbon emissions trading': A dominant firm with competitive fringe model", J Energy Policy, vol. 35, no. 8, pp. 4200-4220, 2007.

[2] M. Kara, S. Syri, A. Lehtilä, S. Helynen, V. Kekkonen, M. Ruska, and J. Forsström, "The impacts of EU CO2 emissions trading on electricity markets and electricity consumers in Finland", J. Energy Econ., vol. 30, no. 2, pp. 193-211, 2008.

[3] A.G. Tsikalakis, and N.D. Hatziargyriou, "Environmental benefits of distributed generation with and without emissions trading", $J$. Energy Policy, vol. 35, no. 6, pp. 3395-3409, 2007.

[4] D. Damien, and Q. Philippe, "European emission trading scheme and competitiveness: a case study on the iron and steel industry", $J$. Energy Econ., vol. 30, no. 4, pp. 2009-2027, 2007.

[5] D. Streimikiene, and I. Roos, "GHG emission trading implications on energy sector in Baltic States", Renewable Sustain. Energy Rev., vol. 13, no. 4, pp. 854-862, 2008.

[6] E. R. Knut, "Incentives and prices in an emissions trading scheme with updating", J. Environ. Econ. Manag., vol. 56, no. 1, pp. 69-82, 2008.

[7] B. Sundarakani, R. de Souza, M. Goh, S. Wagner, and S Manikandan "Modeling carbon footprints across the supply chain", Int. J. Prod. Econ., vol. 128, no. 1, pp. 43-50, 2010.

[8] S. Bode, "Multi period emissions trading in the electricity sector winners and losers", J. Energy Policy, vol. 34, no. 6, pp. 680-91, 2006.

[9] S. Benjaafar, Y. Z. Li, and M. Daskin, "Carbon footprint and the management of supply chains: Insights from simple models", University of Minnesota: USA, Working Paper, 2010.

[10] M.I. Piecyk, and A.C. Mckinnon, "Forecasting the carbon footprint of road freight transport in 2020", Int. J. Prod. Econ., vol. 128, no. 1 , pp. 31-42, 2010

(C) Tang and Song; Licensee Bentham Open.

This is an open access article licensed under the terms of the Creative Commons Attribution Non-Commercial License (http://creativecommons.org/licenses/by-nc/3.0/) which permits unrestricted, non-commercial use, distribution and reproduction in any medium, provided the work is properly cited. 